Editorial

\title{
Reuse: Fashion or future?
}

\section{Introduction}

Good ideas seldom die. During World War 2, the British Ministry of Information urged households to "make-do-and-mend" as a means to use scarce resources efficiently via repair and reuse in times of rationing. Wartime families became expert at stretching scarce resources and this prudence still prevails amongst many older people. This ethos was recast by a British retailer (John Lewis) to reflect concerns of economic recession in 2009; suggestions included how to prolong the life of electrical and electronic gadgets.

In less economically developed nations, make-do-and-mend is a way of life. Used goods have long been valued for repair or for components that can reused. Used goods and components are often traded via established commercial structures and markets; repair and reuse provides income for substantial numbers of poor and marginalized workers. The fact that it also facilitates greater material recovery is a bonus.

In developed countries, buying "second hand" via local newspaper advertisements or charity shops was once symptomatic of a limited budget. Consumers can be reluctant to purchase used items because of concerns about product quality and longevity. Consumers are also influenced by fashion changes, marketing of new products, the availability of cheap new products, and new products with improved efficiency. These "barriers" to reuse are diminishing as the circular economy gains traction: reuse, refurbishment and repair have again come into focus. Purchase of "pre-loved" or "pre-owned" items is a lifestyle choice as well as a financial decision. Auction-style websites are thriving, as are high street shops that buy and sell furniture, textiles, games and electronic goods for reuse by consumers. Buying "vintage", "repurposing" and "upcycling" are fast becoming de rigueur.

So why has reuse come back into focus and is it here to stay this time?

\section{Political impetus}

In the European Union (EU), the Waste Framework Directive 2008/98/EC sets out concepts and definitions related to waste management. Under this Directive:

- Reuse is defined as "any operation to by which products or components that are not waste are used again for the same purpose for which they were conceived" and

- Preparing for reuse is defined as "checking, cleaning or repairing recovery operations, by which products or components of products that have become waste are prepared so that they can be re-used without any other pre-processing."
Reuse is important for waste prevention as it extends the life of products or components, deferring or eliminating the need to manufacture new products. The UK's Local Government Association (2014) estimated that 615,000 tonnes of material that is currently landfilled or incinerated in the UK could be reused. As well as saving UK tax payers $>£ 60$ million (US\$80 million) each year, the resale value of these goods, and reusable goods that are recycled, is about $£ 375$ million (US\$490 million).

Numbers like this attract political attention. The EU has put reuse at the heart of its Environment Action Programme to 2020. The recast of Directive 2012/19/EE on Waste Electrical and Electronic Equipment (WEEE) obliges EU member states to prioritize reuse at the earliest stages of e-waste take-back, separate WEEE for reuse, and enable access for refurbishment centres. Revised reporting now enables reuse to count towards collection targets within the business-to-business and business-to-consumer markets. In England and Wales, updated guidance on when a material is considered waste or not now - for the first time - includes reuse; “If a material hasn't been discarded, it isn't waste". Many European municipal authorities have formed reuse-based partnerships with charities and community groups to facilitate training opportunities, jobs and income to disadvantaged groups - all of which enable progress towards a more resource-efficient economy.

\section{The business imperative}

Manufacturers and the primary retail sector have historically resisted reuse for commercial reasons, but are changing. The EUfunded ZeroWIN project (www.zerowin.eu) demonstrated that industrial networks can successfully establish new circular supply chains. A ZeroWIN case study demonstrated how reuse of ICT equipment could be facilitated in small-and-medium sized enterprises using a resource exchange internet platform. Likewise, the USA's National Materials Marketplace (http://materialsmarketplace.org/) has brought together companies to avoid waste by reusing undervalued materials via an online database.

More organisations and businesses are focusing on reuse. For the commercial reuse sector, the potential profitability for reuse relies on goods being collected and channeled cost-effectively to hubs. Countries with large and concentrated populations are increasingly able to collect and bulk materials for reuse in an economically viable manner because comprehensive collection networks with more regular and predictable supplies, higher throughputs and ready access to markets are becoming easier to establish. The benefits of reuse gained include cost savings via waste management improvements, revenue by selling serviceable but unwanted equipment, easier compliance with waste regulations, reduction 
of environmental impacts, and reputational enhancement. Some businesses now buy reused items because of increased consumer confidence generated by reuse standards such as ISO 9001:2008, BSI-PAS 141 and the European WEEELABEX standards.

\section{The private economy}

Trading (reuse) of items when they are no longer wanted or needed has historically been via second-hand shops and market stalls, bring-and-buy sales, swap shops and car boot sales. The effort involved for an affluent seller can often be deemed too great for the reward received. For a potential buyer, there are risks of purchasing unsafe or unusable items without an acceptable guarantee or after-sales support. During times of hardship, such trading methods become more popular - and are now easier. The Internet has transformed people's ability to trade used items. eBay is a global phenomenon. Most second-hand shops use online trading to supplement and complement their physical presence. The Internet also enables reuse to thrive in a less commercial way. People and organisations now routinely sell, give away or swap goods via organizations such as Freecycle (www.freecycle.org), Preloved (www.preloved.co.uk) and Shpock (www.shpock.com).

\section{The social economy}

Third Sector Organizations (TSOs) are social enterprises in the community or voluntary ("not-for-profit") sectors. They have often found it difficult to get involved in reuse programmes, relying on political or philanthropic support for initial funding and subsequently finding it difficult to become financially self-sustaining. Increased political and societal momentum, larger and more secure supplies of reused items, and the development of infrastructure and reuse standards mean that TSOs now make a valuable but often unrecognised and under-appreciated contribution to reuse (Curran and Williams, 2010). They aim to supply low-cost household items to people in hardship and provide opportunities for long-term unemployed and other socially-excluded individuals to gain practical skills and re-engage with society, and for volunteering.

Globally, well-known TSOs involved in reuse programmes include: Oxfam (international); Bright Sparks (Australia); RepaNet (Austria); Emmaüs (France); Farsi Prossimo (Italy); EKON (Poland); Frip Ethique (Senegal); Computeraid (South Africa); Macken (Sweden); Furniture Re-use Network (UK); The ReUse People of America (USA). To indicate the scale of activity in this sector, the UK's Charity Retail Association (2016) estimates that:

- There are 10,200 charity shops in the UK with $>217,000$ volunteers.

- $85 \%$ of goods sold in charity shops are from donations.

- Charity shops raise more than $£ 300$ million annually for good causes.

The contribution of TSOs to the social economy is clearly massive and their contribution to reuse is huge and probably under-estimated.

\section{Conclusions}

There are many benefits when we reuse - political, commercial, social, environmental and economic. But even though reuse is a highly preferred process within the waste hierarchy, barriers and questions remain. Reuse is dependent on goods being collected and made available to the next user; sufficiently high quality and durable goods need to be put onto the primary market initially.
In-built obsolescence and price competitiveness can lead to products of lower quality and reduced lifespan, with lower potential for their eventual reuse. The variety of products on the market means that the diversion and preparation of products and components for re-use will remain a labour-intensive activity for the foreseeable future. Societal preferences, peer-pressure and the desire for image-orientated products can, in practice, inhibit reuse of some potentially reusable items (e.g. clothing, furniture, e-goods). Economic barriers impede reuse of technically reusable items notably the low price of new goods, and a lack of developed markets for some used goods. There is debate concerning the relative potential benefits of purchasing a new, more efficient appliance and the benefits of reuse. Critics insist that reuse is just delaying time to disposal via landfill or incineration.

But times are changing. Global population is growing and key resources are becoming scarcer and more expensive to secure, prompting decision-makers to embrace circular economy concepts. We are starting to quantify the benefits of reuse in new ways that capture the attention of society. The Internet and novel, rapid delivery systems are transforming our ability to sell used goods easily and quickly. The barriers to reuse are coming down and the impetus to reuse more and better is increasing.

\section{References}

Charity Retail Association, 2016. Charity Shops. <http://www.charityretail.org.uk/ charity-shops/> (date of last access 25/08/2016).

Curran, A., Williams, I.D., 2010. The role of furniture and appliance re-use organisations in England and Wales. Resour. Conserv. Recycl. 54, 692-703.

Local Government Association, 2014. Routes to Reuse: Maximizing Value from Reused Materials. <http://www.local.gov.uk/documents/10180/5854661/LGA +Routes+to+Reuse+FINAL+FINAL.PDF/5edd19ba-7c13-47c5-b019-97a352846863> (date of last access 25/08/2016).

I.D. Williams P.J. Shaw

Centre for Environmental Science, Faculty of Engineering and the Environment, University of Southampton, Highfield, Southampton, Hampshire SO17 1BJ, UK E-mail addresses: idw@soton.ac.uk (I.D. Williams), ps@soton.ac.uk (P.J. Shaw)

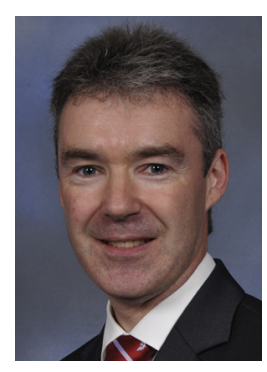

Professor Ian Williams is Associate Dean (Enterprise) at the Faculty of Engineering \& the Environment, University of Southampton.

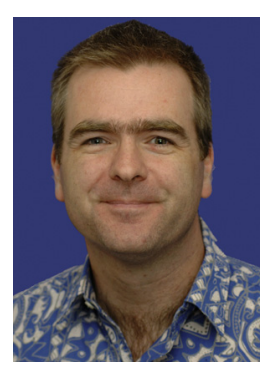

Dr Peter Shaw is Associate Professor in Environmenta Science at the Faculty of Engineering \& the Environment, University of Southampton. 